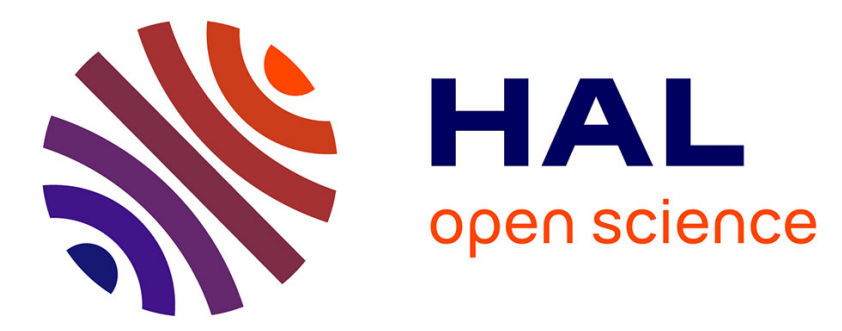

\title{
On functional signatures of bare and coated formwork skin surfaces
}

\author{
N. Spitz, N. Coniglio, M. El Mansori, A. Montagne, S. Mezghani
}

\section{To cite this version:}

N. Spitz, N. Coniglio, M. El Mansori, A. Montagne, S. Mezghani. On functional signatures of bare and coated formwork skin surfaces. Construction and Building Materials, 2018, 189, pp.560-567. hal-01876403

\section{HAL Id: hal-01876403 \\ https://hal.science/hal-01876403}

Submitted on 18 Sep 2018

HAL is a multi-disciplinary open access archive for the deposit and dissemination of scientific research documents, whether they are published or not. The documents may come from teaching and research institutions in France or abroad, or from public or private research centers.
L'archive ouverte pluridisciplinaire HAL, est destinée au dépôt et à la diffusion de documents scientifiques de niveau recherche, publiés ou non, émanant des établissements d'enseignement et de recherche français ou étrangers, des laboratoires publics ou privés. 


\title{
On functional signatures of bare and coated formwork skin surfaces
}

\author{
$\underline{\text { N. Spitz }}{ }^{1}$, N. Coniglio ${ }^{1}$, M. El Mansori ${ }^{1}$, A. Montagne ${ }^{2}$, S. Mezghani $^{3}$
}

\begin{abstract}
${ }^{1}$ Arts et Métiers ParisTech d'Aix-en-Provence, Laboratory of Mechanics, Surface and Materials Processing (MSMP-EA7350), 2 cours des Arts et Métiers, 13617 Aix-en-Provence - France

${ }^{2}$ Arts et Métiers ParisTech de Lille, Laboratory of Mechanics, Surface and Materials Processing, 8 Boulevard Louis XIV, 59800 Lille - France

${ }^{3}$ Arts et Métiers ParisTech de Châlons-en-Champagne, Laboratory of Mechanics, Surface and Materials Processing, Rue Saint-Dominique, 51000 Châlons-en-Champagne - France
\end{abstract}

\begin{abstract}
The sticking of the concrete on metallic formworks during building construction generates many concrete wall defects. Several solutions have been proposed, among which surface lubrication and polymeric coatings are commonly applied. In this paper, the main functional signatures of a steel formwork skin and a polymeric coating were determined to understand their effect on the concrete sticking. The topographical, chemical and mechanical signatures of the surfaces were characterized at near-surface regions. The top of the steel formwork a $10 \mu$ m-thick layer is constituted of two oxides each one having specific tribological properties. Adding the polymeric coating on the formwork skin surface lowers its surface tension, which lowers the sticking by reducing the wettability. Moreover, the smaller roughness of the coating limits the susceptibility of mechanical anchoring. Nevertheless, scratch testing suggests a short durability of the polymeric coating due to its weak resistance to abrasion.
\end{abstract}

Key-words Concrete, skin formwork functionality, Formwork-concrete interface, roughness measurement, scratch testing 


\section{Introduction}

The vast majority of reinforced concrete walls are today built with formworks that maintain the poured concrete during its curing. The formworks are composed of a skin fastened on a rigid structure. Bare steel skins are largely common on construction sites for their sturdiness and their long life span. Nevertheless, the skin surface characteristics will be partially transferred to the cured concrete surface [1]. Subsequently, other skin materials such as wood, plywood, and polymeric coatings [1] are used for improving the concrete wall quality by modifying the superficial interactions between the concrete and the skin.

Superficial interactions with the skin initiate as soon as the concrete is poured through the formation of a boundary layer. This layer formed in the skin asperities is an aqueous solution composed of the fine particles contained in the cement-filler mixture. The subsequent physicochemical interactions and mechanical anchoring of the concrete to the skin [2]-[6] cause the formation of many aesthetic defaults such as discoloration, micro-bulling, and concrete breaking [1][3] that are visible on the surface of concrete walls after formwork removal operations. The required restoration operations are unfortunately costly and timeconsuming and are unnecessary if a weak negligible skin-concrete adhesion is achievable.

The adhesion of the concrete on the skin may possibly arise from electrical bonding [4][5] and chemical bonding through the $\mathrm{Ca}(\mathrm{OH})_{2}$ formation [4]-[6]. The interfacial bonding depends partly on the water-cement ratio [7], the polymer additives [5][7][8] and the filler substitutes [7]. The concrete adhesion is partially avoided by modifying the skin surface through the condensation of a water layer [9], the application of a polymer coating [4], or the spreading of release agents [10]-[13] prior to concrete pouring. The lubricant family, i.e. vegetal or mineral [11][12], the environment temperature [10] and the application mode [13] are also of major importance.

Few works have investigated the effect of the skin superficial characteristics with the concrete ability to adhere to the skin. The adhesion is avoidable with a controlled skin roughness that is low enough to avoid mechanical anchoring and high enough to avoid 
capillary forces [2]-[5] or with a controlled skin chemistry using a special galvanized superficial treatment [6]. The wear resistance to the concrete abrasion is reduced by smoothing the surface [14]. Despite these works, the topic of adhesion as it applies to skin-concrete interactions remains a contentious subject, particularly with regard to identifying the skin superficial characteristics that would ideally avoid concrete adhesion without lubricant spreading.

The present work investigates the surface characteristics of a bare and a coated mild steel formwork skins that are used on-site for their small adhesion with the concrete and good surface finish. Using the sessile drop method, the solid surface tensions were determined and correlated to the topographic and chemical signature of the skins. A scratch test procedure was specifically developed for quantifying the wear resistance of the skins. Accordingly, the experimental results of the scratch tests were implemented into different models to provide a link between the skin wear resistance and the shear stress to remove the surface layer from the steel substrate.

\section{Experimental details}

\subsection{Materials}

Mild steel samples were prepared from $5 \mathrm{~mm}$-thick formwork skins that are used in the field. Skin coupons of $50 \times 50 \mathrm{~mm}^{2}$ were cut by laser at various positions on the formwork skins so as to provide a statistically significant coupon population. In addition, a commercial polymer coating used on formworks on-site was applied on several mild steel coupons for laboratory-scale characterization.

The chemical analysis of the steel skin surface was performed using scanning electron microscopy (SEM) in conjunction with X-ray diffraction (XRD). A nickel layer was deposited on the coupon surfaces to protect them from the deteriorations induced by the mechanical polishing. The coupons were immersed in the Electroless Nickel Plating Solution at a 
temperature between $71^{\circ} \mathrm{C}$ and $82^{\circ} \mathrm{C}$ with a deposition rate of $10 \mu \mathrm{m} \cdot \mathrm{h}^{-1}$. Cross sections were afterwards cut, ground, and mechanically polished using a $0.05 \mu$ m-diamond suspension. Metallic surface were observed with a scanning electron microscope (SEM) JEOL JSM-7001F using secondary electrons for the surface topography and backscattered electrons for the chemical contrast (compo mode). Micrographs of metallic samples were obtained in high vacuum $\left(\approx 10^{-4} \mathrm{~Pa}\right)$ with a $15 \mathrm{kV}$-acceleration voltage at a $10 \mathrm{~mm}$ working distance. With the micrographic observations by SEM, energy dispersive spectroscopy (EDS) was performed using an Oxford Instruments X-max analyzer with a $20 \mathrm{~mm}^{2}$-detection surface. EDS spectra were analyzed by means of the software INCA. Following the SEM measurements, the crystallographic phases were determined using a Siemens D500 X-ray diffractometer. A chromium anode with a $\mathrm{Cr}-\mathrm{K} \alpha$ wavelength $\lambda=0.22911 \mathrm{~nm}$ radiation and diffraction angles $2 \theta$ from $40^{\circ}$ to $160^{\circ}$ at $40 \mathrm{kV}$ and $30 \mathrm{~mA}$ were used. A vanadium filter was added in diffractometer to absorb the $\mathrm{Cr}-\mathrm{K} \beta$ radiation. The pics detection was performed according to $2 \theta$ diffraction angles through the Bragg's law.

The polymeric coating was analyzed using thermogravimetric analysis (TGA), differential scanning calorimetry (DSC) and Fourier Transform-Infrared (FT-IR) Spectroscopy. TGA testing was carried out using the TA Instruments TGA Q500 thermogravimetric analyzer with a sample mass of $4.2 \mathrm{mg}$ and under a $50 \mathrm{ml} \cdot \mathrm{min}^{-1}$ flow rate of nitrogen. The thermal composition was performed from room temperature to $900{ }^{\circ} \mathrm{C}$ at a heating rate of $20^{\circ} \mathrm{C} \cdot \mathrm{min}^{-1}$. The DSC characterization was performed on a TA Instruments DSC Q10 calorimeter on $3 \mathrm{mg}$ sample heated at $10^{\circ} \mathrm{C} \cdot \mathrm{min}^{-1}$ from $-80^{\circ} \mathrm{C}$ to $190^{\circ} \mathrm{C}$ temperature range and under a $50 \mathrm{ml} \cdot \mathrm{min}^{-1}$ flow rate of nitrogen. The weight fraction crystallinity is given by:

$$
X_{c}=\frac{\Delta H_{f}}{\Delta \mathrm{H}_{\mathrm{f}}^{\circ}}
$$

where $\Delta H_{f}$ is the heat of fusion of the measured sample determined at endothermic melting peak and $\Delta H_{f}^{\circ}$ is the enthalpy of fusion of $100 \%$ crystalline material. Finally, the FT-IR analysis was realized on a Fisher FT-IR spectrometer from Perkin Elmer in transmission and ATR 
(Attenuated Total Reflection) modes. The sample was in contact with a diamond/ZnSe crystal. Four scans per mode were recorded over the range $4000-600 \mathrm{~cm}^{-1}$ with a spectral resolution of $4 \mathrm{~cm}^{-1}$.

\subsection{Roughness measurements}

The surface topography was measured using a white-light interferometry microscope (WLIM) VEECO NT3300 over a $4 \times 4 \mathrm{~mm}^{2}$ area. The surface was sampled at $2052 \times 2052$ points with a $1.9 \mu \mathrm{m}$ step scale along $\mathrm{X}$ - and $\mathrm{Y}$-directions. 15 analyses have been carried out on 3 surfaces for each formwork skin. A multi-scale characterization of the surfaces was preliminary performed in order to determine a relevant measurement scale. Surface roughness profiles were sampled in frequency components from $3.10^{-2}$ to $8 \mathrm{~mm}^{-1}$ using the decomposition approach of continuous wavelets [15]. Above a scale of $1 \mathrm{~mm}$, the surfaces showed fractal domains. Therefore, in an aim of obtaining representative data acquired in a small duration time, areas of $4 \times 4 \mathrm{~mm}^{2}$ were chosen.

The arithmetic mean height $\left(S_{a}\right)$, the root mean square height $\left(S_{q}\right)$, the peaks material volume $\left(V_{m p}\right)$, the core void volume $\left(V_{v c}\right)$ and the valley void volume $\left(V_{v v}\right)$ were computed according to the ISO 25178 norm [16]. $\mathrm{V}_{\mathrm{mp}}, \mathrm{V}_{\mathrm{vc}}$ and $\mathrm{V}_{\mathrm{vv}}$ are calculated in three intervals: 0 to $10 \%, 10$ to $80 \%$ and 80 to $100 \%$ of the bearing ratio respectively [17].

\subsection{Wettability measurement}

Sessile drop wettability was characterized out on the Morphoscan from Michalex Tribometrix according to the norm AFNOR EN 828 [18]. Measurements were performed without cleaning the surface so as to maintain the skin in the in-field superficial conditions. Drops were deposited in an environment of $22 \pm 1{ }^{\circ} \mathrm{C}$ temperature and $54 \pm 2 \%$ relative humidity. Two liquids, demineralized water and glycerol, were used with characteristics given in Table 1. A syringe of inside diameter of $4.6 \mathrm{~mm}$ equipped with a needle of $0.8 \mathrm{~mm}$ outside 
diameter was used to achieve the deposition of $5 \pm 1 \mu \mathrm{L}$ droplets. The capillary length $K$ (Table 1) is given by [19]:

$$
\mathrm{K}=\sqrt{\frac{\gamma}{\rho g}}
$$

where $\gamma$ is liquid superficial tension, $\rho$ liquid density, and $g$ gravitational acceleration. The droplets have a radius in the $1.26 \pm 0.36 \mathrm{~mm}$ range, smaller than the capillary length (Table 1 ), so that gravity is negligible. The static droplet shape on the sample's surface was recorded as a 720x480 pixels image ten seconds after the drop was deposited. Contact angles were measured to an accuracy of $\pm 2^{\circ}$ using the open source image processing program ImageJ. Ten droplets of each liquid were deposited at different locations on the surface of each sample to obtain an arithmetic medium value of the contact angles. The contact angle was measured after the droplet spreading, meaning that the provided values are the advancing contact angles.

Table 1. Surface tensions of liquids used [18].

\begin{tabular}{|c|c|c|c|c|c|}
\hline Liquid & $\begin{array}{c}\text { Superficial Tension } \\
\left(\mathrm{mN} \cdot \mathrm{m}^{-1}\right)\end{array}$ & $\begin{array}{c}\text { Dispersed Component } \\
\left(\mathrm{mN} \cdot \mathrm{m}^{-1}\right)\end{array}$ & $\begin{array}{c}\text { Polar Component } \\
\left(\mathrm{mN} \cdot \mathrm{m}^{-1}\right)\end{array}$ & $\begin{array}{c}\text { Density } \\
(\mathrm{kg} / \mathrm{m} 3)\end{array}$ & $\begin{array}{c}\text { Capillary } \\
\text { Length }(\mathrm{m})\end{array}$ \\
\hline $\begin{array}{c}\text { Demineralized } \\
\text { water }\end{array}$ & 72.80 & 21.80 & 51.00 & 1000 & 0.0027 \\
\hline Glycerol & 63.40 & 37.00 & 26.40 & 1260 & 0.0023 \\
\hline
\end{tabular}

The analysis is founded upon the Owens-Wendt model [20] for a perfectly flat homogeneous solid surface wetted by a liquid drop:

$$
\sigma_{\mathrm{SV}}=\sigma_{\mathrm{LS}}+\sigma_{\mathrm{LV}} \cos \theta
$$

where $\sigma_{S V}$ and $\sigma_{L V}$ are the solid-vapor and liquid-vapor superficial tensions, respectively. Eq.8 is rewritten by implementing the polar (subscript $P$ ) and dispersed (subscript $D$ ) components of surface tensions $\sigma_{S V}$ and $\sigma_{L V}[18]$ : 


$$
\frac{(1+\cos \theta) \cdot \sigma_{\mathrm{LV}}}{2 \sqrt{\sigma_{\mathrm{LV}}^{\mathrm{D}}}}=\sqrt{\sigma_{\mathrm{SV}}^{\mathrm{P}}} \cdot \sqrt{\frac{\sigma_{\mathrm{LV}}^{\mathrm{P}}}{\sigma_{\mathrm{LV}}^{\mathrm{D}}}}+\sqrt{\sigma_{\mathrm{SV}}^{\mathrm{D}}}
$$

where $\theta$ is the contact angle for a given liquid drop. Linear best-fitting of $\frac{(1+\cos \theta) \cdot \sigma_{\mathrm{LV}}}{2 \sqrt{\sigma_{\mathrm{LV}}^{\mathrm{D}}}}$ versus $\sqrt{\frac{\sigma_{\mathrm{LV}}^{\mathrm{D}}}{\sigma_{\mathrm{LV}}^{\mathrm{D}}}}$ estimates the polar $\sigma_{S V}^{P}$ (slope) and dispersed $\sigma_{S V}^{D}$ (residue) components. The surface energy of the substrate is afterward calculated as the sum of the polar $\sigma_{S V}^{P}$ and dispersed $\sigma_{S V}^{D}$ components.

\subsection{Mechanical characterization}

Hardness measurements were performed using the Morphoscan from Michalex Tribometrix equipped with a Berkovich diamond tip. The loadings were performed at a constant strain rate of $0.05 \mathrm{~s}^{-1}$ up to a maximum load of $150 \mathrm{mN}$ for the steel skin and $5.5 \mathrm{mN}$ for the polymer coating. Nanoindentations were achieved with a penetration depth smaller than $1 \mu \mathrm{m}$, namely less than $10 \%$ of the thickness of the top layer, to avoid the subtract influence. Load-displacement curves were processed using the Oliver and Pharr method [21], [22]. Nevertheless, the absence of superficial polishing prior to nanoindentation induced a large scatter in the calculated mechanical properties.

The wear resistance of the steel skin and polymeric coating was evaluated using a Scratch Tester Millenium 200, TriboTechnic equipped with a Rockwell C diamond indenter with a $200 \mu \mathrm{m}$-radius hemispherical tip. The scratch test was carried out from 0 to $100 \mathrm{~N}$ at a loading rate of $3.3 \mathrm{~N} \cdot \mathrm{s}^{-1}$ and a scratch speed of $0.7 \mathrm{~mm} \cdot \mathrm{s}^{-1}$ along a $20 \mathrm{~mm}$ path. The critical normal load was determined by identifying a sudden change in the tangential and normal force behaviors. After completion of the tests, the usual optical microscopic observations of the scratch profile were fulfilled with topographic measurements using a white-light interferometric microscope (WLIM) VEECO NT3300. 


\section{Results}

\subsection{Composition analysis of mild steel skin}

SEM observations of the skin cross section (Fig.1) revealed a non-uniform oxide layer with a total thickness of $11.4 \mu \mathrm{m}$. This superficial oxide film was composed of a top and bottom sub-layers of 3.8 and $7.6 \mu \mathrm{m}$ thick, respectively. The boundary of the superposed sublayers was highlighted by a thin white region rich in nickel, which resulted from the diffusion of the nickel protective layer through the oxide top sub-layer during the Electroless Nickel Plating. This suggests a very porous top sub-layer and a discontinuity between the two sublayers.

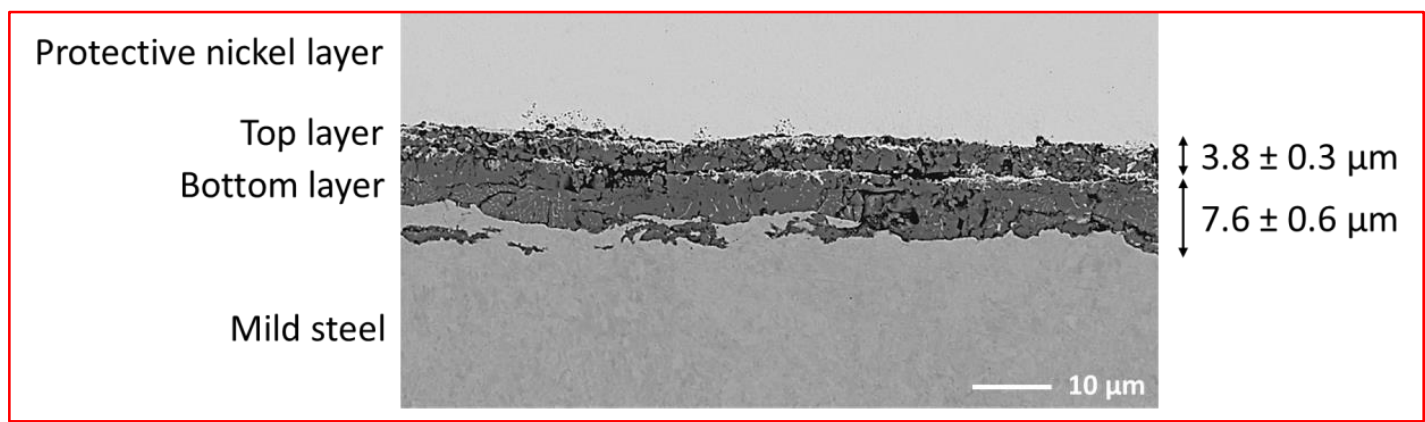

Fig.1. SEM micrograph (COMPO mode) of the cross-section steel formwork skin.

EDS analyses performed on each sub-layer revealed that iron and oxygen were the main elements of these sub-layers. The approximate iron and oxygen weight contents are summarized in Table 2, highlighting that the compositions are close to the theoretical oxygen weight percentages of $\alpha-\mathrm{Fe}_{2} \mathrm{O}_{3}$ and $\mathrm{Fe}_{3} \mathrm{O}_{4}\left(\% \mathrm{w}_{\mathrm{O}}^{\mathrm{Fe}_{2} \mathrm{O}_{3}}=30.1 \%\right.$ and $\left.\% \mathrm{w}_{\mathrm{O}}^{\mathrm{Fe}_{3} \mathrm{O}_{4}}=27.7 \%\right)$. The $\% \mathrm{w}_{\mathrm{O}}^{\mathrm{Fe}_{2} \mathrm{O}_{3}}$-to- $\% \mathrm{w}_{\mathrm{O}} \mathrm{Fe}_{3} \mathrm{O}_{4}$ ratios of the theoretical and EDS-measured contents are both equal to 0.92 , suggesting that the oxides present were indeed $\alpha-\mathrm{Fe}_{2} \mathrm{O}_{3}$ (hematite) and $\mathrm{Fe}_{3} \mathrm{O}_{4}$ (magnetite) in the top and bottom sub-layers, respectively. The experimental excess of oxygen in the EDS measurements may possibly arise from the impurities not accounted for. 
Table 2. Oxygen and iron weight percentages obtained by EDS for the steel formwork skin.

\begin{tabular}{|c|c|c|}
\cline { 2 - 3 } \multicolumn{1}{c|}{} & $\%_{\mathbf{0}}^{\text {EDS }}$ & $\% \mathbf{w}_{\mathrm{Fe}}^{\text {EDS }}$ \\
\hline Bottom layer & $31.9 \pm 0.2$ & $67.1 \pm 0.3$ \\
\hline Top layer & $34.5 \pm 0.9$ & $63.6 \pm 1.2$ \\
\hline Steel substrate & $<1$ & $>98$ \\
\hline
\end{tabular}

The suggested presence of $\alpha-\mathrm{Fe}_{2} \mathrm{O}_{3}$ and $\mathrm{Fe}_{3} \mathrm{O}_{4}$ were reinforced by XRD analyses (Fig.2). Aside from the peaks from steel, the surface exhibited a significant crystallinity. The steel substrate is crystallized in a body-centered cubic crystal structure, $\alpha$-ferrite (JCPDS 87-0721). High peaks of $\alpha-\mathrm{Fe}_{2} \mathrm{O}_{3}$ (hematite) and $\mathrm{Fe}_{3} \mathrm{O}_{4}$ (magnetite) were detected (JCPDS 33-0664 and JCPDS 87-2334, respectively). Since the $\alpha-\mathrm{Fe}_{2} \mathrm{O}_{3}$ oxide has important lubricating properties while the harder $\mathrm{Fe}_{3} \mathrm{O}_{4}$ oxide has a good wear resistance [23]-[25], the presence of both oxides explain in part the good tribological property of the formwork skin surface.

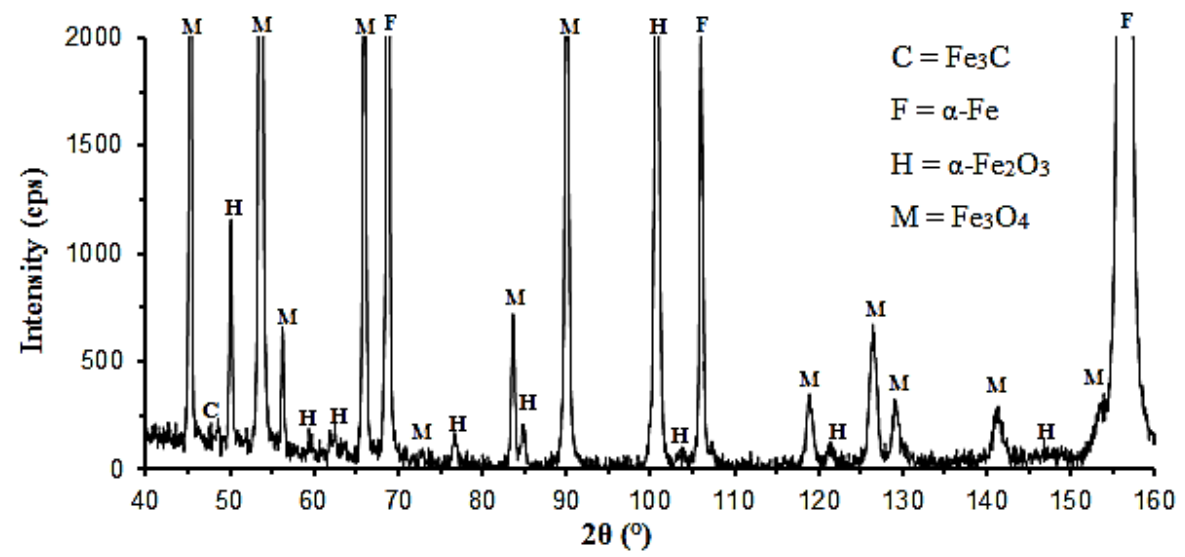

Fig.2. XRD spectrum showing the phase composition of the formwork skin.

\subsection{Composition analysis of polymeric coating}

Optical observations revealed 3 sub-layers composing the polymeric formwork coating

(Fig 3). The $160 \mu$ m-thick top layer is the functional layer in contact with the concrete. The 
bottom layer is the adhesive layer to stick the coating on the steel formwork surface. In between is the coating wear indicator appearing when the top functional layer must be replaced.

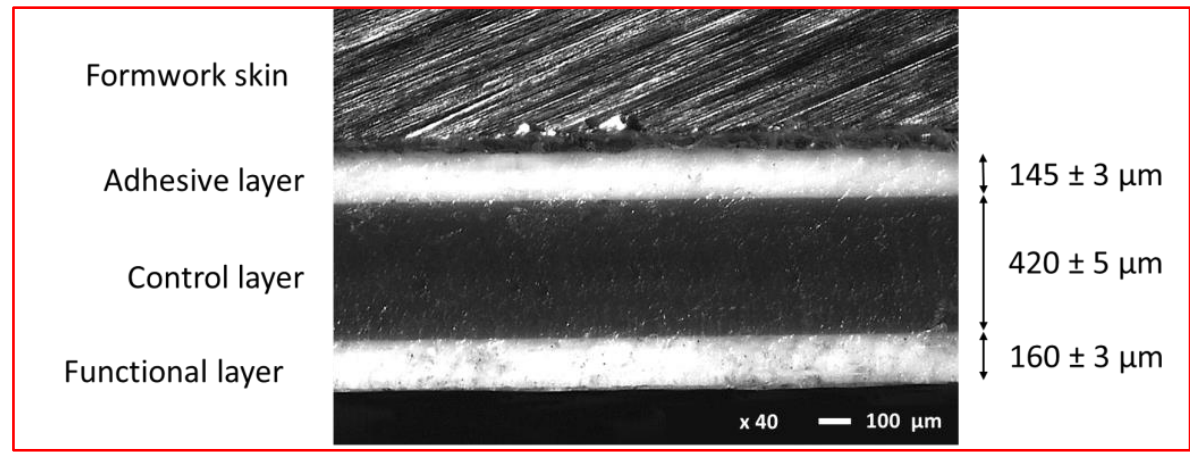

Fig.3. Optical micrograph of the coating put on the formwork skin.

Thermal analyses were performed on the upper functional layer using the thermogravimetric analysis (TGA) and the differential scanning calorimeter (DSC) (Fig.4). The TGA thermogram (Fig.4a) revealed a huge mass loss from 350 to $500{ }^{\circ} \mathrm{C}$ with $12 \%$ residual mass in form of a powder containing the inorganic filler material. The TGA curve is similar to the one for the polypropylene (PP) [26].

The DSC curve revealed an endothermic peak of fusion at $164^{\circ} \mathrm{C}$ during heating (Fig.4b), in agreement with the melting temperature of PP [26], [27]. The measured enthalpy of fusion was $\Delta \mathrm{H}_{\mathrm{f}}=70 \mathrm{~J} \cdot \mathrm{g}^{-1}$ to be compared to the enthalpy of fusion of $100 \%$ crystalline PP (198 $\mathrm{J} \cdot \mathrm{g}^{-1}$ [27]). The formwork PP coating was thus crystallized at about $35 \%$. A small endothermic peak preceding the fusion at $122^{\circ} \mathrm{C}$ (magnified view in Fig.4b) may possibly be due to a modification in the polymer structure [28].

The intense IR bands near to $3000 \mathrm{~cm}^{-1}$ and between $1500-650 \mathrm{~cm}^{-1}$ in the ATR-FTIR spectrum of the sample (Fig.4c) are specific at polypropylene [29]. The additional absorption peaks comprise between 1750 and $1550 \mathrm{~cm}^{-1}$ could be due to some anhydride groups $(-\mathrm{C}=0)$ [27]-[30]. However, it was difficult to determine the exact PP grafted anhydride given that the peaks were shifted in relation to pure anhydrides and possibly due to molecular structural modifications. The PP grafted anhydride is of interest for improving the sticking between the 
polymer and the associated filler. In addition the transmission-FTIR spectrum of the residual filler after TGA testing (Fig.4d) showed band wavenumbers of $3470 \mathrm{~cm}^{-1}$ attributed to $-\mathrm{OH}$ bonds and of 2083 and $1641 \mathrm{~cm}^{-1}$ attributed to $\mathrm{H}-\mathrm{O}-\mathrm{H}$ bonds of the PP matrix [31]. The 1080 and $900 \mathrm{~cm}^{-1}$ bands may possibly correspond to the Al-O-H and $\mathrm{Al}-\mathrm{O}$ bonds of boehmite $\mathrm{AlOOH}$ particles, respectively [32]. The composition of the commercial polymer coating was in agreement with patent WO 2016/059193 A1.

In summary, the polymeric coating is a composite material at PP-grafted-anhydride matrix with about $12-15 \%$ of alumina filler. The release of water by the boehmite at $480^{\circ} \mathrm{C}$ [33] was not visible because this one was combined with the degradation of PP, explaining a shift of the degradation upper temperature from 450 to $500^{\circ} \mathrm{C}$ [26]. PP was possibly chosen for its small water absorption and chemical inertia, leading to little adherence of the concrete on the coating. Additions of alumina particles improve the coating properties by improving the wear properties and reducing ultraviolet sensitivity.
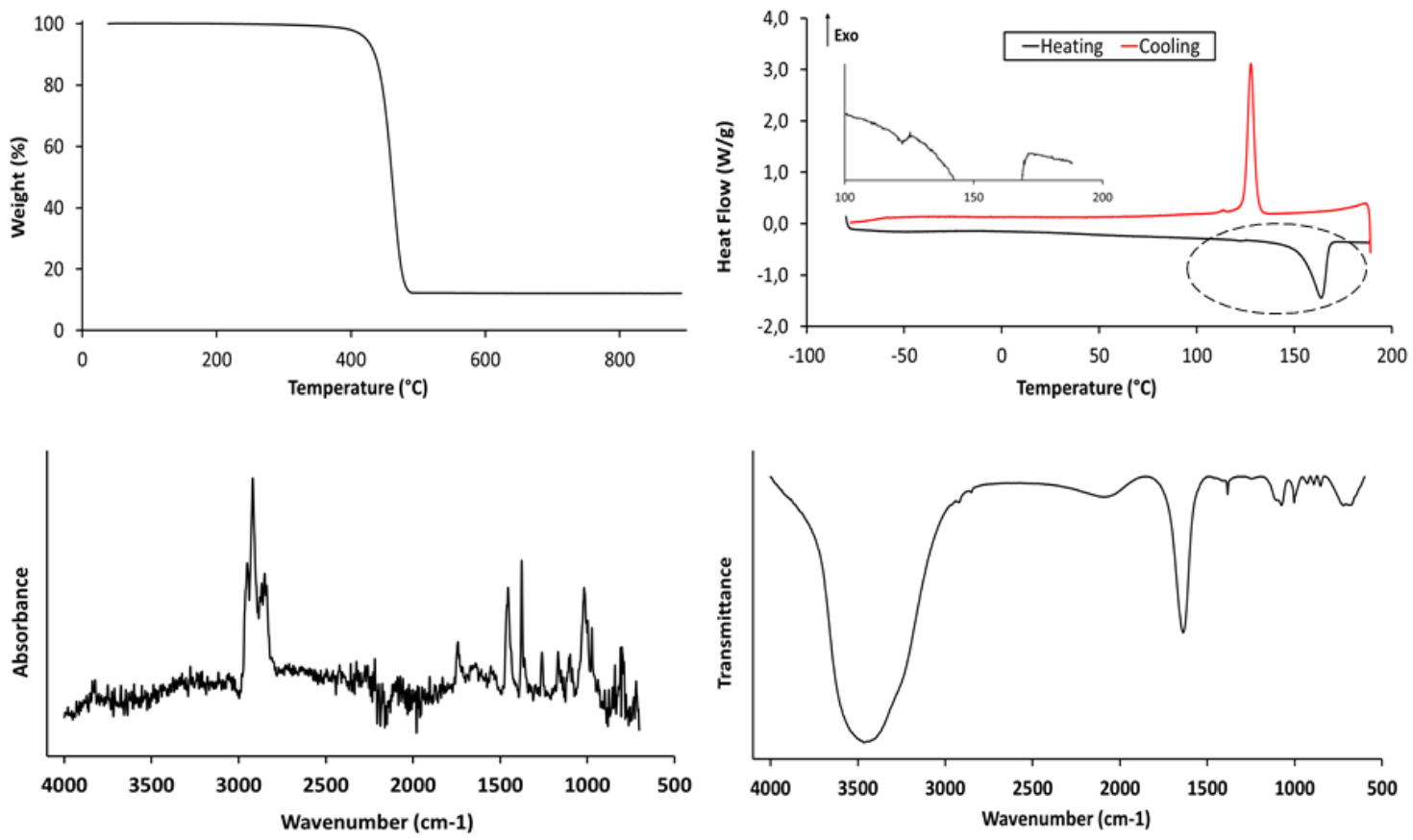

Fig.4. (a) TGA thermogram, (b) DSC curves, (c) ATR-FTIR spectrum, (d) Transmission-FTIR spectrum after TGA of the formwork coating. 


\subsection{Surface topography characterization}

The 3D profiles of the bare formwork skin and the coating are showed in Fig.5 which revealed that the coated surface was more heterogeneous with deeper grooves. Roughness parameters calculated on these profiles are summarized in Table 3.

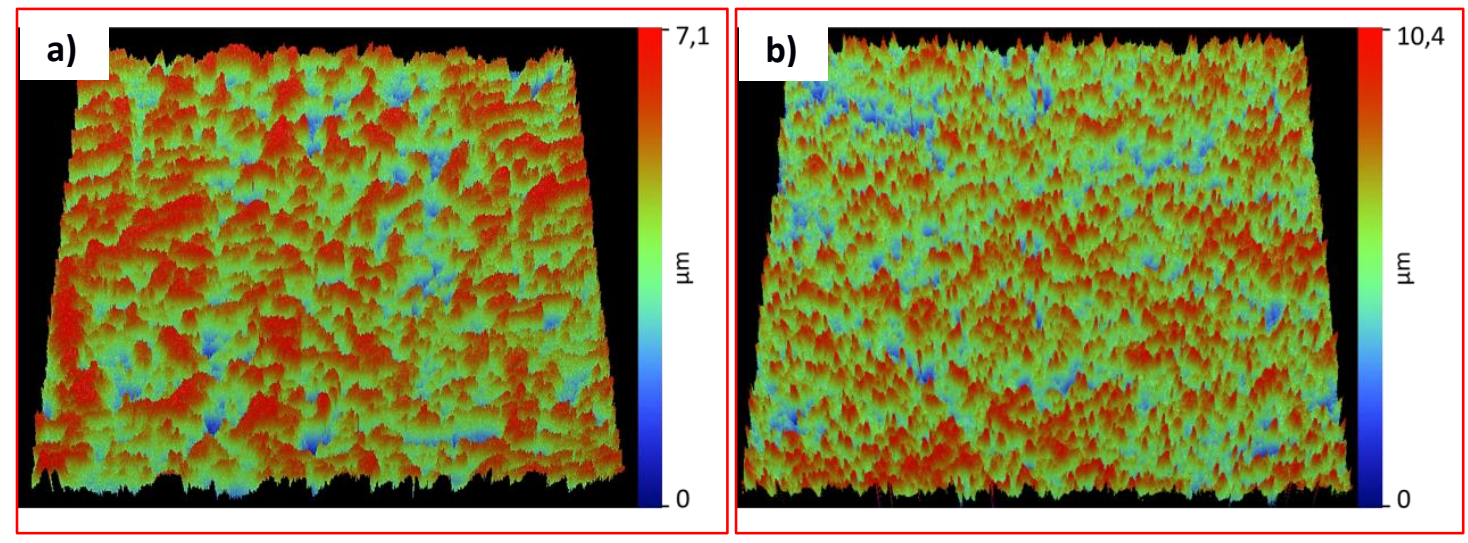

Fig.5. Surface topography (WLIM) in 3D representation $\left(4 \times 4 \mathrm{~mm}^{2}\right)$ : (a) Bare formwork skin, (b)

$$
\text { Coating formwork }
$$

The $S_{a}$ parameter, associated to the ability to trap cement particles, was $0.9 \mu \mathrm{m}$ for the bare formwork skin, in agreement with data reported by Libessart et al. [11][12], and $2.5 \mu \mathrm{m}$ for the coating. According to the cement particle size distribution measured by ASTMsponsored round-robin tests [34], around $5 \%$ and $15 \%$ of the finest cement particles would penetrate into the surface of the bare and coated formwork respectively, suggesting an enhanced cement-to-formwork mechanical adherence [35] and friction [36] with the use of the coating.

The peaks material volume was minimum for the bare formwork skin $(50 \pm 10$ $\mathrm{nm}^{3} / \mathrm{nm}^{2}$ ), suggesting a lower peaks surface wear. Moreover, the $V_{\mathrm{vc}}$ and $V_{\mathrm{vv}}$ parameters correlate to the amount of cement particles after normal running-in wear and excessive wear, respectively, and subsequently the retention properties of the surface. The higher $V_{v c}$ and $V_{v v}$ values for the coating suggest that more small cement particles would infiltrate at the core and at the bottom of valleys and be blocked. 
Table 3. 3D Roughness parameters of the steel formwork skin

\begin{tabular}{|c|c|c|c|c|c|}
\cline { 2 - 6 } \multicolumn{1}{c|}{} & Sa $(\mu \mathrm{m})$ & $\mathrm{Sq}(\mu \mathrm{m})$ & $\mathrm{V}_{\mathrm{mp}}\left(\mathrm{nm}^{3} / \mathrm{nm}^{2}\right)$ & $\mathrm{V}_{\mathrm{vc}}\left(\mu \mathrm{m}^{3} / \mu \mathrm{m}^{2}\right)$ & $\mathrm{V}_{\mathrm{vv}}\left(\mathrm{nm}^{3} / \mathrm{nm}^{2}\right)$ \\
\hline $\begin{array}{c}\text { Bare } \\
\text { formwork } \\
\text { skin }\end{array}$ & $0.9 \pm 0.1$ & $1.1 \pm 0.1$ & $50 \pm 10$ & $170 \pm 10$ & $150 \pm 20$ \\
\hline $\begin{array}{c}\text { Formwork } \\
\text { Coating }\end{array}$ & $2.5 \pm 0.4$ & $3.3 \pm 0.5$ & $80 \pm 10$ & $230 \pm 30$ & $210 \pm 30$ \\
\hline
\end{tabular}

\subsection{Wettability}

The wettability of bare formwork bare skin and the coating were measured with the sessile drop method Table 4. Contact angles of $93 \pm 1^{\circ}$ and $104 \pm 4^{\circ}$, with a $95 \%$ confident range of $1^{\circ}$ and $2^{\circ}$ according to the Student T-distribution, were measured with glycerol and water respectively for the bare metallic skin. The calculated bare skin surface energy is 15,6 $\mathrm{mN} . \mathrm{m}^{-1}$, according to Eq.9, lower to the value found in Libessart et al. work [12] despite similar roughness. The respective water and glycerol contact angles for the formwork coating were 71 $\pm 1^{\circ}$ and $80 \pm 2^{\circ}$ with a $95 \%$ confident range of $1^{\circ}$ respectively. The resulting coating surface energy was $38.7 \mathrm{mN} \cdot \mathrm{m}^{-1}$. The water contact angle is about half the one measured on pure PP [37], which may possibly due to the presence of polar anhydrides that enhance the water affinity. The surface energy is related to the ability of material to interact with the cement paste. A surface with a low surface energy should have subsequently smaller work of adhesion of the concrete if no chemical reaction occurred. The higher surface energy of the polymeric coating compared to the bare formwork skin would suggest a better tendency to attract concrete.

Table 4. Contact angles for the bare formwork skin and the formwork coating.

\begin{tabular}{|l|c|c|}
\hline & Bare formwork skin & Formwork coating \\
\hline Glycerol & $93 \pm 1^{\circ}$ & $80 \pm 2$ \\
\hline Water & $104 \pm 4^{\circ}$ & $71 \pm 1^{\circ}$ \\
\hline
\end{tabular}




\subsection{Mechanical characterization}

Instrumented nanoindentation testing has been only performed on cleaned bare samples. The steel skin was not polished to enable the real surface characterization, despite the porous surface. For the mechanical characterization of the steel skin, we considered one single layer of oxide with hardness equal to the overall influence of each individual oxide layer. The hardness of the oxide layer was measured to be approximately $12 \pm 2 \mathrm{GPa}$ (for penetration depths less than $1000 \mathrm{~nm}$ ) with a steel substrate hardness measured at $2.5 \mathrm{GPa}$.

Scratch tests performed with a Rockwell C indenter on the bare formwork skin are summarized in Fig.6. Three zones delimited by the applied normal force were identified along the scratch (Table 5). For normal forces smaller than $15 \mathrm{~N}$, the oxide layer did not detach from the steel substrate and the only mechanical response is the oxide layer deformation. Inbetween 15 and $25 \mathrm{~N}$ (from point $\mathbf{A}$ to $\mathbf{B}$ in Fig.6c), the increasing friction and the lateral pileups formation were correlated with the intermittent rupture of the oxide layer. The full fracture of the oxide layer was observed above $25 \mathrm{~N}$ (point B in Fig.6c) with a scratch depth deeper than the oxide thickness. The steel was deformed with an oxide layer flattened and smoothed (Zone 3). At the maximal force of $100 \mathrm{~N}$, the friction force was $180 \mathrm{~N}$ at a scratching depth of $46 \mu \mathrm{m}$ and the final lateral pile-ups formed by the steel deformation are shown in Fig.7. 


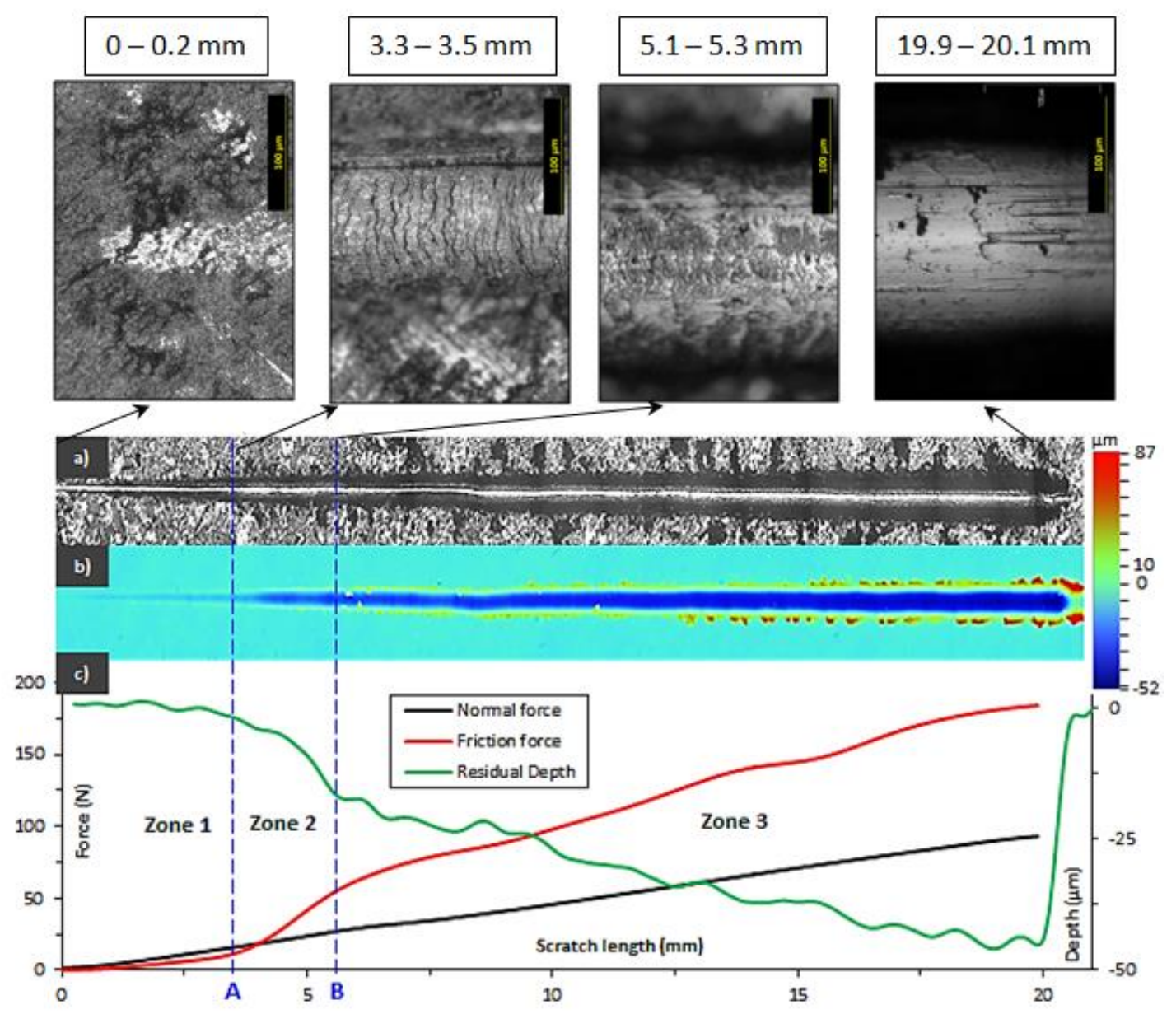

Fig.6. a) Micrograph of the scratch track with indication of position range along

scratch, b) WLMI surface after test, c) Results of scratch test with the depth of the scratch for the steel formwork skin.

Table 5. Determination of the critical load of the bare formwork surface.

\begin{tabular}{|c|c|c|c|c|}
\hline Zone & Positon (mm) & Critical load (N) & Friction (N) & Depth $(\boldsymbol{\mu m})$ \\
\hline A & $3.4 \pm 0.5$ & $15 \pm 3$ & $9 \pm 2$ & -1.9 \\
\hline B & $5.2 \pm 0.4$ & $25 \pm 3$ & $58 \pm 6$ & -16 \\
\hline
\end{tabular}




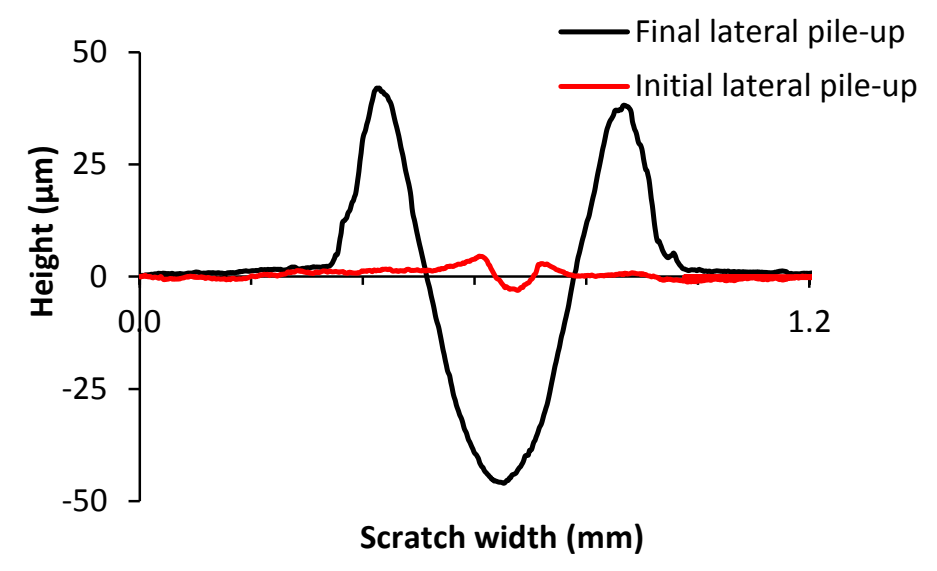

Fig.7. Initial and final lateral pile-up during scratch test at begin of zone 2 and end of zone 3, respectively for the bare steel formwork skin.

Instrumented nanoindentation testing has been performed on the PP coating. The Young modulus and hardness were measured using the Oliver et Pharr method [21] with calculated values of 0.2 and $4.3 \mathrm{GPa}$ respectively at $1000 \mathrm{~nm}$ depth. These values are higher than the $0.04 \mathrm{GPa}$ hardness and an $0.81 \mathrm{GPa}$ elastic modulus measured of $20 \mu \mathrm{m}$-thick pure PP film at $5 \mu \mathrm{m}$ depth [38], possibly because of the alumina additions (H $\approx 12 \mathrm{GPa}$ and $\mathrm{E} \approx 350 \mathrm{GPa}$ [39]).

Scratch tests performed with a Rockwell C indenter on the PP coating are summarized in Fig.8. Four zones delimited by the applied normal force were identified along the scratch (Table 6). For normal forces smaller than $6 \mathrm{~N}$, the coating top layer only deforms viscoelastically and recovers quickly after the load removal. In-between 6 and $45 \mathrm{~N}$ (from point $\mathbf{A}$ to B in Fig.8c), the tangential force increased linearly with the normal force and the PP coating deformed plastically with lateral pile-up formation. From 45 to $90 \mathrm{~N}$ (from point B to C in Fig.8c), the high normal load is sufficient to sink the top layer into the underlying wear indicator layer and simultaneously the tangential force increasing rate slowed down, the lateral pile-up reduces, and the acoustic emission rise up. This phenomenon was highlighted by the transition between the fish scale deformation (zone 2) and the ploughing (zone 3 ) observed at the scratch bottom. This transition agrees with scratch observations on PP films 
[40][41]. The regularly spaced wave-like lines in the zone 2 may possibly arise from the formation of shear bands on the polymer [41]. At the end, the top layer was roughly sunk into the control layer with a final depth higher than $120 \mu \mathrm{m}$ at loads above $90 \mathrm{~N}$ (point C in Fig.8c). It must be noticed that, even at the highest normal load of $95 \mathrm{~N}$, no pull-off of the functional top layer from the wear indicator layer was observed, suggesting that the PP coating wears only by abrasion during the concrete pouring.

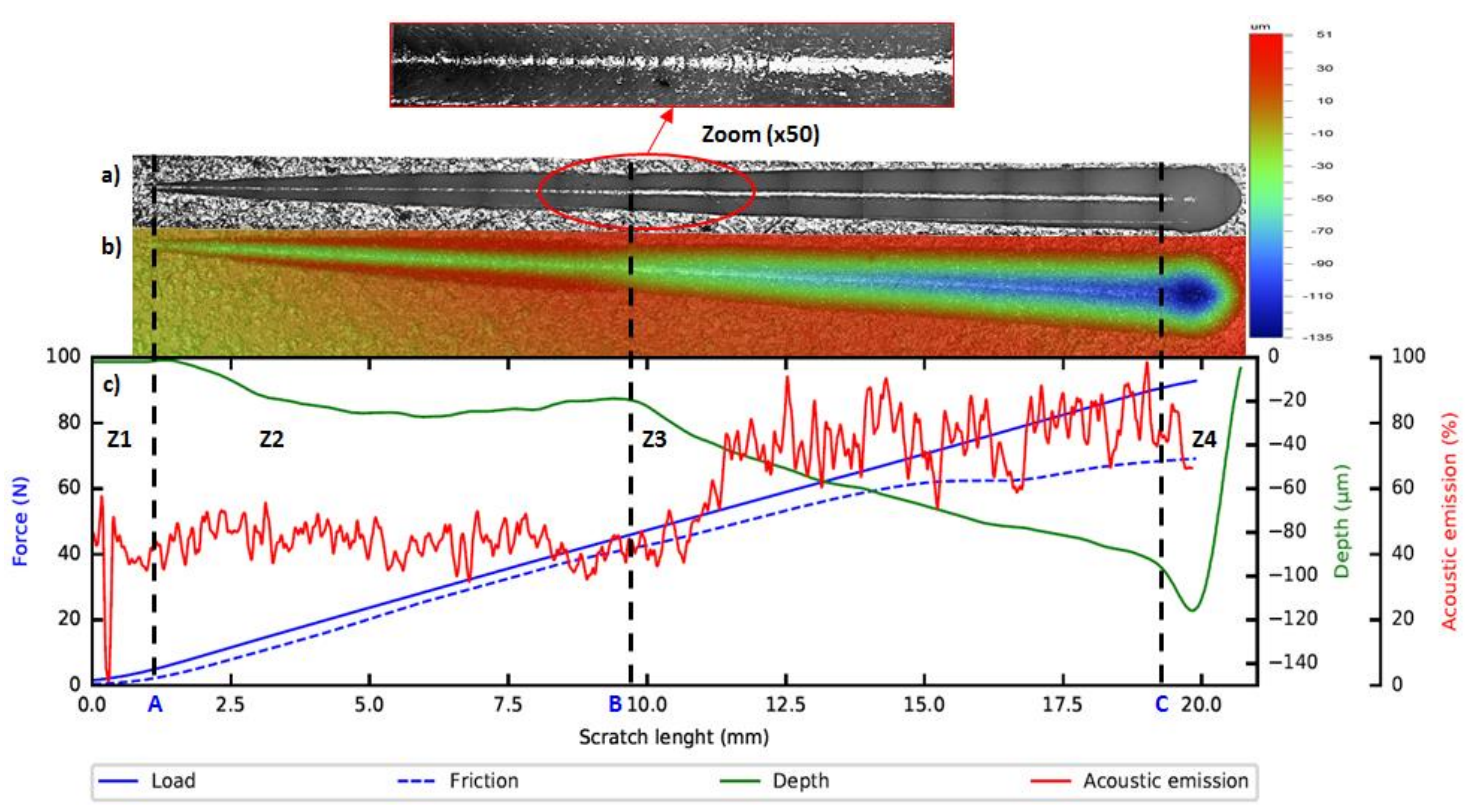

Fig8. a) Micrograph of the scratch track, b) WLMI surface after test, c) Results of scratch test with the depth of the scratch for the formwork coating.

Table 6. Determination of the critical load of the formwork coating.

\begin{tabular}{|c|c|c|c|c|}
\hline Zone & Positon (mm) & Critical load (N) & Friction (N) & Depth ( $\mu \mathrm{m})$ \\
\hline A & $1.2 \pm 0.2$ & $6 \pm 1$ & $2.5 \pm 0.5$ & -8 \\
\hline B & $9.2 \pm 0.5$ & $45 \pm 3$ & $40 \pm 3$ & -25 \\
\hline C & $19.2 \pm 0.5$ & $90 \pm 3$ & $68 \pm 5$ & -100 \\
\hline
\end{tabular}




\section{Discussion}

Scratch tests were carried out to study the mechanical behavior and the adhesion of the top layer on the formwork. Because no pull-off was observed on the PP coating, the modeling is limited to the oxide film on the bare formwork skin. To calculate the critical shear stress between the oxide film and the material, several scratch models exist, as indicated in a review on the subject [42]. In the present work, we paid attention on scratch models that accounts for the track width (or contact radius) and the critical load to calculate the shear stress. The first model applied is proposed by Benjamin and Weaver [43] and it gives a measure of adhesion in terms of a critical shear stress $\tau_{\text {crit }}$ by :

$$
\tau_{\text {crit }}=\frac{\mathrm{H}_{\mathrm{s}} \mathrm{a}_{\text {crit }}}{\sqrt{\mathrm{R}^{2}-\mathrm{a}_{\text {crit }}{ }^{2}}}
$$

where $H_{s}$ is the hardness of the substrate, $R$ is the tip radius and $a_{\text {crit }}$ is the contact radius between tip and surface at the critical load $L_{c r i t}$, which may be approximated by the half width of the scratch. The width of the track $(d)$ at the critical load is $55 \mu \mathrm{m}$ so $a_{\text {crit }}=27.5 \mu \mathrm{m}$, leading to a critical shear stress $\tau_{c r i t}$ of $0.3 \mathrm{GPa}$. Ollivier and Matthews [44] replaced $H_{S}$ in Eq.10 by $L_{\text {crit }} / \pi a^{2}$ giving:

$$
\tau_{\text {crit }}=\frac{\mathrm{L}_{\text {crit }}}{\pi \mathrm{a}_{\text {crit }} \sqrt{\mathrm{R}^{2}-\mathrm{a}_{\text {crit }}{ }^{2}}}
$$

This model estimated the critical shear stress $\tau_{\text {crit }}$ to a value of $0.9 \mathrm{GPa}$. A third model proposed by Laugier [45] calculates the critical shear stress from the compressive stress $\sigma_{x}$ under the leading edge of the indenter:

$$
\tau_{\text {crit }}=\frac{\sigma_{\mathrm{x}} \mathrm{a}_{\text {crit }}}{\mathrm{R}} \quad \text { with } \quad \sigma_{\mathrm{x}}=\frac{\mathrm{L}_{\text {crit }}}{2 \pi \mathrm{a}_{\text {crit }}{ }^{2}}\left\{\left(4+v_{\mathrm{s}}\right) \frac{3 \pi \mu}{8}-\left(1-2 v_{\mathrm{s}}\right)\right\}
$$

in which $\nu_{s}$ is Poisson's ratio of the substrate ( 0.3 for the steel) and $\mu$ is the friction coefficient between the indenter and the film equals to 0.6 at the critical load. We found $\tau_{\text {crit }}=1.1 \mathrm{GPa}$ using this model. On average, with these three models the critical shear stress is $0.8 \mathrm{GPa}$. The last model presented by Benjamin and Weaver [43] is based on the friction force acting on the indenter $F_{x}$ during the scratch test and $F_{x}$ is defined by the following equation:

$$
F_{x}=\frac{d^{3} H_{s}}{12 R}+\frac{\pi \tau d}{4}-d t H_{c}
$$


The first term is the force required to deform the substrate. The second component is the force needed to remove the coating from the substrate, i.e. the force needed to shear the adhesive bonds between film and substrate. This term is comparable to the value of critical load. And the third component is the plowing force required to push aside the sheared film [43]. With a friction force of $9 \mathrm{~N}$, the critical shear stress between the oxide layer and the steel is equal to $6.7 \mathrm{GPa}$. This value is one order of magnitude greater than the shear stress calculated by the former models. The calculated critical shears according to the different scratch models are summarized in Table 7.

Table 7. Scratch models applied to experimental data for bare formwork skin

\begin{tabular}{|c|c|c|c|c|}
\hline Scratch Model & Eq. & Calculated $\tau_{\text {crit }}(\mathrm{GPa})$ & Coating-substrate & Ref \\
\hline$\tau_{\text {crit }}=\frac{\mathrm{H}_{\mathrm{s}} \mathrm{a}_{\text {crit }}}{\sqrt{\mathrm{R}^{2}-\mathrm{a}_{\text {crit }}{ }^{2}}}$ & 10 & 0.4 & Metallic film on Hard substrate & [43] \\
\hline$\tau_{\text {crit }}=\frac{\mathrm{L}_{\text {crit }}}{\pi \mathrm{a}_{\text {crit }} \sqrt{\mathrm{R}^{2}-\mathrm{a}_{\text {crit }}{ }^{2}}}$ & 11 & 0.9 & $\begin{array}{l}\text { Diamond-like carbon on Soft } \\
\text { substrate }\end{array}$ & [44] \\
\hline$\tau_{\text {crit }}=\frac{\sigma_{x} a_{\text {crit }}}{R}$ & 12 & 1.1 & General coating-substrate & [45] \\
\hline$F_{x}=\frac{d^{3} H_{s}}{12 R}+\frac{\pi \tau d}{4}-d t H_{c}$ & 13 & 6.7 & Metallic film on Hard substrate & [43] \\
\hline
\end{tabular}

According to the equation (Eq.13) of the Benjamin and Weaver second model, the critical load can be recalculated with the second component by the following equation:

$$
\mathrm{L}_{\text {crit }}=\frac{\pi \tau \mathrm{d}}{4}
$$

With the Benjamin and Weaver second model, we found a Lcrit value (16 N) very close to the experimental value of $15 \pm 3 \mathrm{~N}$. This model was developed for metallic thin films deposited on hard glass subtracts considering Van der Waal's forces between the coating and the material. Our oxide layer is formed by dissociation of water molecules into hydrogen and oxygen that diffuses through the substrate, thus the oxide-to-substrate adhesion is not with Van der Walls 
forces. Therefore, the correlation between the model and the experiment is due to delamination. Indeed, the model assumes a stripping mode for the layer removal, this mode being the one observed by optical microscopy on the scratched specimens. The Benjamin and Weaver second model is the only model to consider the tangential force in their equation and the proposed fracture mechanic of the oxide layer is similar with our sample. Besides, the recalculated critical load with this model is very close to the experimental value. Therefore, the Benjamin and Weaver second model seems to be the correct scratch model for the oxide layer detachment on the steel substrate.

The friction stress at the concrete-formwork interface was estimated in the 10 to 30 kPa range according to other works [8], [14], [36], [46], [47]. This friction stress is $10^{6}$ orders of magnitude smaller than the calculated critical shear stress for the delamination of the oxide layer from the formwork substrate. Consequently, because of their hard oxide layer and strong resistance to delamination, the bare steel formwork skins remain a good solution for long operating lifespan providing the double oxide layer is still present at the surface. Despite its susceptibility to abrasion, the PP coating could become a new short-term alternative for high-quality wall fabrication because of its chemical inertia to concrete.

\section{Conclusion}

In this work, a steel formwork skins largely used on construction sites and a new PPcoating have been studied throughout various experimental tests. Afterwards, the functionality of surfaces in regards to concrete adherence, lubrication efficiency, and wear resistance has been compared and following conclusions can be drawn:

- The roughness measurements showed that the coated surface was more heterogeneous and could potentially trap three times more cement particles at the core and at the bottom of valleys.

- The steel formwork skins would have a better wear resistance of the surface peaks. The presence of an abrasive hematite external layer and the high delamination stress of the 
oxide layer to the substrate indicated that the formwork skin is more wear resistant than the coating.

- The polymer coating possessed a surface energy twice as strong as the metallic skin, suggesting that the concrete adhesion to the polymer would be very high.

Future work will focus on the life time evolution of a formwork skin and the influence of the concrete formulation on the concrete-formwork adherence.

\section{Acknowledgements}

The authors gratefully acknowledge the contribution of colleagues of Arts et Metiers ParisTech for their technical support and those received from the colleagues of the Procedes et Ingenerie en Mecanique et Materiaux Laboratory (PIMM) for their formwork coating analyzes.

\section{References}

[1] CimBéton, "T49 : La maîtrise esthétique des parements en béton," Collect. Tech., 2005.

[2] "L’adhérence du béton au coffrage," Bull. du Cim., vol. 38, no. 8, 1970.

[3] "Décollement de la pellicule de ciment," Bull. du Cim., vol. 37, no. 22, 1969.

[4] A. Mazkewitsch and A. Jaworski, "The adhesion between concrete and formwork," Adhes. between Polym. Concr. entre polymères béton, Springer US, pp. 67-72, 1986.

[5] J. Mlodecki, "Adhesion forces of polymer modified concrete and plain concrete to steel in moulds and in reinforced concretes," Adhes. between Polym. Concr. entre polymères béton, Springer US, pp. 55-63, 1986.

[6] D. G. Montgomery and A. Samarin, "Adhesion between concrete and treated or untreated flat metal surfaces," MRS Proceedings, Cambridge Univ. Press, no. 114, p. $263,1987$.

[7] X. Fu and D. D. L. Chung, "Effects of water-cement ratio, curing age, silica fume, polymer admixtures, steel surface treatments, and corrosion on bond between concrete and steel reinforcing bars," ACl Mater. J., vol. 95, pp. 725-734, 1998. 
[8] S. Bouharoun, Y. Vanhove, C. Djelal, P. De Caro, and I. Dubois, "Interactions between superplasticizer and release agents at the concrete/formwork interface," Mater. Sci. Appl., vol. 3, pp. 384-389, 2012.

[9] N. Goudjil, Y. Vanhove, C. Djelal, and H. Kada, “Development of a new demoulding process based on concrete polarization," 15th Int. Conf. Exp. Mech., pp. 1-16, 2012.

[10] G. Baty and R. Reynolds, "Release Agents-How they work," Concr. Int., vol. 19, no. 9, pp. 52-54, 1997.

[11] L. Libessart, C. Djelal, and P. De Caro, "Influence of the type of release oil on steel formwork corrosion and facing aesthetics," Constr. Build. Mater., vol. 68, pp. 391-401, 2014.

[12] L. Libessart, P. De Caro, C. Djelal, and I. Dubois, "Correlation between adhesion energy of release agents on the formwork and demoulding performances," Constr. Build. Mater., vol. 76, pp. 130-139, 2015.

[13] C. Djelal, A. Y. Vanhove, A. D. Chambellan, and A. P. Brisset, "Influence of the application method of release agents on thickness of mould oils," Mater. Struct., 2009.

[14] C. Djelal, Y. Vanhove, and A. Magnin, "Tribological behaviour of self compacting concrete," Cem. Concr. Res., vol. 34, pp. 821-828, 2004.

[15] H. Zahouani, S. Mezghani, R. Vargiolu, and M. Dursapt, "Identification of manufacturing signature by 2D wavelet decomposition," Wear, vol. 264, no. 5-6, pp. 480-485, 2008.

[16] AFNOR, "Spécification géométriquedes produits (GPS) - État de surface : surfacique Partie 2 : termes, définitions et paramètres d'états de surface," NF EN ISO 25178-2, 2012.

[17] AFNOR, "Spécification géométrique des produits (GPS) - État de surface : surfacique Partie 3 : Opérateurs de spécification," NF EN ISO 25178-3.

[18] AFNOR, “Adhésifs-Mouillabilité-Détermination par mesurage de l'angle de contact et de l'énergie superficielle libre de la surface," NF EN 828, 2013.

[19] P. G. De Gennes, F. Brochard-Wyart, and D. Quéré, Capillarity and wetting phenomena: 
drops, bubbles, pearls, waves. Springer Science \& Business Media, 2003.

[20] D. K. Owens and R. C. Wendt, "Estimation of the surface free energy of polymers," J. Appl. Polym. Sci., vol. 13, no. 8, pp. 1741-1747, 1969.

[21] W. C. Oliver and G. M. Pharr, "Measurement of hardness and elastic modulus by instrumented indentation: Advances in understanding and refinements to methodology," J. Mater. Res., vol. 19, no. 01, pp. 3-20, 2004.

[22] W. C. Oliver and G. M. Pharr, "An improved technique for determining hardness and elastic modulus using load and displacement sensing indentation experiments," J. Mater. Res., vol. 7, no. 6, pp. 1564-1583, 1992.

[23] C. Vergne, C. Boher, R. Gras, and C. Levaillant, "Influence of oxides on friction in hot rolling: Experimental investigations and tribological modelling," Wear, vol. 260, no. 910, pp. 957-975, 2006.

[24] K. J. Chin, H. Zaidi, and T. Mathia, "Oxide film formation in magnetized sliding steel/steel contact-analysis of the contact stress field and film failure mode," Wear, vol. 259, no. 1-6, pp. 477-481, 2005.

[25] X. Yu, Z. Jiang, D. Wei, C. Zhou, Q. Huang, and D. Yang, "Tribological properties of magnetite precipitate from oxide scale in hot-rolled microalloyed steel," Wear, vol. 302, no. $1-2$, pp. $1286-1294,2013$.

[26] M. Sahli and J. C. Gelin, "Development of a feedstock formulation based on polypropylene for micro-powder soft embossing process of 316L stainless steel microchannel part," Int. J. Adv. Manuf. Technol., vol. 69, no. 9-12, pp. 2139-2148, 2013.

[27] A. Oromiehie, H. Ebadi-Dehaghani, and S. Mirbagheri, "Chemical modification of polypropylene by maleic anhydride: melt grafting, characterization and mechanism," Int. J. Chem. Eng. Appl., vol. 5, no. 2, pp. 117-122, 2014.

[28] H. H. S. Corporation, "DSC Measurement of Polypropylene," no. 86, pp. 1-2, 2008.

[29] E. Andreassen, "Polypropylene," vol. 2, no. August, 1999.

[30] B. De Roover, M. Sclavons, V. Carlier, J. Devaux, R. Legras, and A. Momtaz, "Molecular 
characterization of maleic anhydride-functionalized polypropylene," J. Polym. Sci. Part A Polym. Chem., vol. 33, no. 5, pp. 829-842, 1995.

[31] C. Liu, K. Shih, Y. Gao, F. Li, and L. Wei, "Dechlorinating transformation of propachlor through nucleophilic substitution by dithionite on the surface of alumina," J. Soils Sediments, vol. 12, no. 5, pp. 724-733, 2012.

[32] D. Y. Li, Y. S. Lin, Y. C. Li, D. L. Shieh, and J. L. Lin, "Synthesis of mesoporous pseudoboehmite and alumina templated with 1-hexadecyl-2,3-dimethyl-imidazolium chloride," Microporous Mesoporous Mater., vol. 108, no. 1-3, pp. 276-282, 2008.

[33] A. Laachachi, M. Ferriol, M. Cochez, J. M. Lopez Cuesta, and D. Ruch, "A comparison of the role of boehmite $(\mathrm{AlOOH})$ and alumina (Al2O3) in the thermal stability and flammability of poly(methyl methacrylate)," Polym. Degrad. Stab., vol. 94, no. 9, pp. 1373-1378, 2009.

[34] C. F. Ferraris, V. A. Hackley, and A. I. Avilés, "Measurement of Particle Size Distribution in Portland Cement Powder: Analysis of ASTM Round Robin Studies," Cem. Concr. Aggregates, vol. 26, no. 2, pp. 1-11, 2004.

[35] N. Spitz, N. Coniglio, M. El Mansori, A. Montagne, and S. Mezghani, "Quantitative and representative adherence assessment of coated and uncoated concrete-formwork," Surf. Coatings Technol., vol. 352, no. March, pp. 247-256, 2018.

[36] S. Bouharoun, "Friction behaviour of fresh concrete in the vicinity of formwork," J. South African Inst. Civ. Eng., vol. 55, no. 3, pp. 10-17, 2013.

[37] E. Masaeli, M. Morshed, and H. Tavanai, "Study of the wettability properties of polypropylene nonwoven mats by low-pressure oxygen plasma treatment," Surf. Interface Anal., vol. 39, pp. 770-774, 2007.

[38] J. Ramirez, "NANOINDENTATION OF Polypropylene Film," NANOVEA a better Meas., no. January 2012, pp. 1-9, 2010.

[39] M. Bhattacharya, R. Chakraborty, A. Dey, A. Kumar Mandal, and A. Kumar Mukhopadhyay, "New observations in micro-pop-in issues in nanoindentation of coarse 
grain alumina," Ceram. Int., vol. 39, no. 2, pp. 999-1009, 2013.

[40] E. Moghbelli, R. L. Browning, W. J. Boo, S. F. Hahn, L. J. E. Feick, and H. J. Sue, "Effects of molecular weight and thermal history on scratch behavior of polypropylene thin sheets," Tribol. Int., vol. 41, no. 5, pp. 425-433, 2008.

[41] M. Wong, A. Moyse, F. Lee, and H. J. Sue, "Study of surface damage of polypropylene under progressive loading," J. Mater. Sci., vol. 39, no. 10, pp. 3293-3308, 2004.

[42] M. H. Blees, G. B. Winkelman, A. R. Balkenende, and J. M. J. den Toonder, "Effect of friction on scratch adhesion testing: Application to a sol-gel coating on polypropylene," Thin Solid Films, vol. 359, no. 1, pp. 1-13, 2000.

[43] P. Benjamin and C. Weaver, "Measurement of Adhesion of Thin Films," Proc. R. Soc. London A Math. Phys. Eng. Sci., vol. 254, no. 1277, pp. 163-176, 1960.

[44] B. Ollivier and A. Matthews, "Adhesion of diamond-like carbon films on polymers: An assessment of the validity of the scratch test technique applied to flexible substrates," J. Adhes. Sci. Technol., vol. 8, no. 6, pp. 651-662, 1994.

[45] M. Laugier, "The development of the scratch test technique for the determination of the adhesion of coatings," Thin Solid Films, vol. 76, no. 3, pp. 289-294, 1981.

[46] S. Bouharoun, P. De Caro, I. Dubois, C. Djelal, and Y. Vanhove, "Effect of a superplasticizer on the properties of the concrete/oil/formwork interface," Constr. Build. Mater., 2013.

[47] C. Djelal, P. De Caro, L. Libessart, I. Dubois, and N. Pébère, "Comprehension of demoulding mechanisms at the formwork/oil/concrete interface," Mater. Struct., vol. 41, pp. 571-581, 2008. 